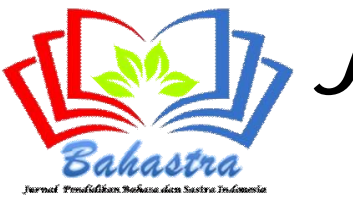

urnal P endidikan B ahasa dan S astra I ndonesia

ISSN: 2550-0848; ISSN Online : 2614-2988

Vol. 4, No. 2, Maret 2020

Situs web:

https:// jurnal.uisu.ac.id/index.php/Bahastra

\title{
PENGGUNAAN BLENDED LEARNING PADA PEMBELAJARAN ERA INDUSTRI 4.0
}

\author{
Yuniarti Maya \\ Universitas Prima Indonesia \\ yunimaya69@gmail.com
}

\begin{abstract}
Abstrak. Era revolusi industri 4.0. yang dikenal dengan istilah era digital melalui teknik penulisan dan penyimpanan data, dimana data yang biasa disimpan secara fisik dan manual bermigrasi ke data digital. Data diprogram dengan Bahasa pemrograman komputer sehingga efektif, efisien dan manageable. Dampak dari digitalisasi terhadap perubahan prilaku sosial pada bidang pekerjaan sangat berpengaruh, maka bisa disebut era disruptif. Era ini menunjukan bahwa ada banyak "kekacauan" dan anti mainstream dari semua sistem kehidupan yang dianggap mapan masa lalu. Perubahan dari beragai variasi pekerjaan yang muncul di era disruptif, maka era ini disebut revolusi industri 4.0. Era dimana revolusi industri saat perang dunia satu dan dua telah berakhir dan berujung pada penjajahan. Dengan tulisan ini guru sebagai ujung tombak pendidikan dapat mendidik peserta didik agar mengelaborasi bagaimana dunia pendidikan menangkap ide gila revolusi industri yang tak bisa ditolak ini, sekaligus mencarikan solusinya. Dalam hal yang lebih spesifik, tulisan ini akan menunjukan bagaimana pembelajaran "Blended Learning" yang direkomendasikan oleh seluruh dunia agar bisa dioperasionalisasikan dalam konteks sekolah dasar sampai tingkat pendidikan tertinggi di Indonesia.
\end{abstract}

Kata Kunci : Blended Learning, Pembelajaran, Era Industry 4.0, Pendidikan Tinggi

Abstract: The era of the industrial revolution 4.0. known as the digital era through data writing and storage techniques, where data that is normally stored physically and manually migrates to digital data. Data is programmed with a computer programming language so that it is effective, efficient and manageable. The impact of digitalization on changes in social behavior in the field of work is very influential, so it can be called the disruptive era. This era shows that there is a lot of "chaos" and anti-mainstream of all living systems that are considered well-established in the past. Changes from a variety of jobs that emerged in the disruptive era, then this era is called the industrial revolution 4.0. The era in which the industrial revolution during world wars one and two had ended and ended in colonialism. With this writing the teacher as the spearhead of education can educate students to elaborate on how the education world catches this crazy idea of an irresistible industrial revolution, as well as finding a solution. In more specific terms, this paper will show how "Blended Learning" learning is recommended by the whole world to be 
operationalized in the context of elementary schools to the highest level of education in Indonesia.

Keywords: Blended Learning, Learning, Industry 4.0 Era,

\section{PENDAHULUAN}

$$
\text { Higher Education }
$$

UU No 20 Tahun 2003 tentang Sistem pendidikan nasional (Sisdiknas) pasal 3 menyatakan bahwa pendidikan nasional berfungsi mengembangkan kemampuan dan membentuk watak serta peradaban bangsa yang bemartabat dalam rangka mencerdaskan kehidupan bangsa, bertujuan untuk berkembangnya potensi peserta didik agar menjadi manusia yang beriman dan bertakwa kepada Tuhan Yang Maha Esa, berahlak mulia, sehat, berilmu, cakap, kreatif, mandiri, dan menjadi warga negara yang demokratis serta bertanggung jawab.

$$
\text { Perkembangan pendidikan }
$$

selalu beriringan dengan perkembangan revolusi industri 4.0. Contoh yang terjadi yaitu dengan teknologi komputerisasi yang tanpa batas. Menurut Airlangga Hartarto selaku Menteri Perindustrian Republik Indonesia mengatakan bahwa kebijakan yang dilakukan oleh pemerintah saat ini adalah melaksanakan peta jalan Making Indonesia 4.0. Salah satu targetnya yaitu menjadikan indonesia masuk dalam 10 besar negara yang memiliki perekonomian terkuat di dunia pada tahun 2030.

Berdasarkan laporan PISA (Programme for International Student Assessment) peringkat pendidikan Indonesia di dunia bertengger di urutan 62 dunia di bidang sains, 63 dunia di bidang matematika, dan 64 dunia di membaca. Masih di bawah Singapura, Vietnam, dan Thailand. PISA sendiri merupakan survei yang menguji kemampuan peserta didik berusia 15 tahun untuk tiga bidang, yakni membaca, matematika, dan sains. Survei ini diinisiasi Organisation for Economic Cooperation and Development (OECD)

Dalam sambutannya di peringatan Hari Pendidikan Nasional yang dirilis di situs resmi Kemendikbud, Menteri Pendidikan dan Kebudayaan Republik Indonesia periode 2015-2019, Prof. Muhadjir Effendi, mengklaim mutu pelayanan pendidikan di Indonesia sudah semakin baik dalam beberapa tahun terakhir ini.

Bagaimana caranya? Dengan meningkatkan kualitas Sumber Daya Manusia di Indonesia sendiri. Rencananya Indonesia merombak kurikulum pendidikan yaitu lebih menekankan sistem STEAM (Science, Technology, Engineering, the Arts, and Mathematices)

Dengan perkembangan teknologi yang semakin cepat dunia pendidikan dituntut untuk bisa atau memakai teknologi dalam melaksanakan pembelajarannya agar semua peserta didik mampu berkompetisi dalam dunia kerja di era revolusi industri 4.0 yang memiliki ketrampilan abad 21 meliputi 4C yaitu creativity, critical thingking, communication dan collaboration. Tidak hanya peserta didik, pengajar pun harus siap menghadapi ini. Bagaimana mungkin peserta didik memiliki ketrampilan tersebut jika dari pihak pengajar belum siap.

Maka dari itu sistem pembelajaranya pun harus disesuaikan, salah satunya yaitu melalui Blended Learning. Kenapa Blended Learning? karena Blended Learning memiliki beberapa kelebihan yaitu efektifitas, awalnya proses belajar mengajar hanya terjadi di ruang kelas, namun sekarang proses belajar mengajar tak terikat oleh 
ruang dan waktu, kemudian dengan Blended Learning maka waktu yang digunakan untuk belajar oleh peserta didik akan lebih lama sehingga peserta didik akan lebih siap memenuhi standarnya.

Jadi dalam menghadapi era rovolusi industri 4.0 di bidang pendidikan untuk mewujudkan cita-cita making indonesia 4.0 harus ada wujud nyata dan usaha keras untuk bisa merealisasikanya.

\section{Guru Sebagai Ujung Tombak Pendidikan 4.0}

Era revolusi industri 4.0 dalam bidang pendidikan merupakan istilah umum yang dipakai oleh para ahli pakar pendidikan untuk menggambarkan beragam cara dalam mengintegrasikan teknologi cyber ke dalam dunia pembelajaran. Pendidikan 4.0 merupakan fenomena yang terjadi sebagai respon terhadap kebutuhan revolusi industri 4.0, di mana manusia dan mesin diselaraskan untuk memperoleh solusi, memecahkan berbagai masalah yang dihadapi, serta menemukan berbagai kemungkinan inovasi baru yang dapat dimanfaatkan bagi perbaikan kehidupan manusia modern abad 21.

Era digitalisasi telah hadir di depan mata dan tidak bisa dihindari, untuk itu guru harus mampu mengendalikannya agar menghadirkan banyak manfaat dan tidak menimbulkan dampak negatif akibat penyalahgunaan teknologi bagi peserta didik. Penanaman nilai agama dan budi pekerti yang kuat harus diselaraskan dalam menyongsong era reolusi 4.0 untuk menghadirkan generasi yang tidak hanya cerdas dalam ilmu pengetahuan dan teknologi, namun juga santun dan cerdas dalam perilaku

Era yang dialami saat ini, siapa pun dituntut untuk mempersiapkan diri dalam menghadapi segala tantangannya. Selain tantangan, era ini pun memberikan peluang bagi siapa pun untuk mendapatkan manfaat terbesar dengan perkembangan teknologi yang telah memasuki revolusi Industri era 4.0. Siapa pun yang mampu beradaptasi dengan situasi saat ini serta mengambil manfaat terbaik yang terus berubah cepat setiap saat, niscaya akan memperoleh kemajuan dalam bidang apapun termasuk dalam pendidikan dan pengajaran atau yang kita kenal bidang pembelajaran.

Guru sebagai ujung tombak pembelajaran harus mampu merencanakan dan melaksanakan PBM yang berkualitas dengan teknologi canggih. Oleh karena itu, diperlukan pembelajaran yang dapat membentuk generasi kreatif, inovatif, serta kompetitif namun juga santun dan cerdas dalam perilaku sesuai dengan tujuan sistem pendidikan nasional. Hal tersebut salah satunya dapat dicapai dengan cara mengoptimalisasi penggunaan teknologi sebagai alat bantu pembelajaran yang diharapkan mampu menghasilkan output yang dapat mengikuti atau mengubah zaman menjadi lebih baik dengan bimbingan dari guru itu sendiri. Indonesia pun perlu meningkatkan kualitas lulusan sesuai dunia kerja dan tuntutan teknologi digital.

\section{Blended Learning Merupakan Model} Pembelajaran 4.0

Menurut Prof. Muhadjir Efendi (Menteri Pendidikan dan Kebudayaan Indonesi) sistem pembelajaran abad 21 merupakan suatu peralihan pembelajaran dimana kurikulum yang dikembangkan saat ini menuntut sekolah untuk merubah pendekatan pembelajaran yang berpusat pada pendidik(teachercentered learning) menjadi pendekatan 
pembelajaran yang berpusat pada peserta didik (student-centered learning) yang menuntut peserta didik harus memiliki kemampuan berpikir kritis, memiliki kreatifitas dan kemampuan yang inovatif, kemampuan dan keterampilan berkomunikasi yang baik, kemampuan kerjasama, dan memiliki kepercayaan diri yang tinggi.

Sistem pendidikan terus mengalami perkembangan dari yang hanya menggunakan sistem konvensional beralih ke sistem yang serba digital yang dikenal dengan pendidikan 4.0. Awalnya proses belajar mengajar hanya terjadi di ruang kelas, namun sekarang proses belajar mengajar tak terikat oleh ruang dan waktu. Sistem pendidikan sekarang yang serba digital menghasilkan suatu metode belajar yaitu Blended Learning. Blended Learning telah populer di kalangan peserta didik Indonesia.

Untuk beralih dari model pembelajaran tatap muka atau bertemu secara langsung, lalu berubah menjadi daring (online) itu sangat membutuhkan effort dan biaya yang tidak sedikit. Namun ini bisa dimulai dengan model Blended Learning. Apa itu Blended Learning? Model Blended Learning adalah pada dasarnya merupakan gabungan keunggulan pembelajaran yang dilakukan secara tatap-muka dan secara virtual.

Menurut Semler

(2005) "Blended Learning combines the best aspects of online learning, structured face-to-face activities, and real world practice. Online learning systems, classroom training, and on-thejob experience have major drawbacks by themselves. The Blended Learning approach uses the strengths of each to counter the others' weaknesses."
Blended Learning adalah sebuah kemudahan pembelajaran yang menggabungkan berbagai cara penyampaian, model pengajaran, dan gaya pembelajaran, memperkenalkan berbagai pilihan media dialog antara fasilitator dengan orang yang mendapat pengajaran. Blended Learning juga sebagai sebuah kombinasi pengajaran langsung (face-to-face) dan pengajaran online, tapi lebih daripada itu sebagai elemen dari interaksi sosial.

Blended Learning adalah suatu cara dalam proses belajar mengajar yang menggabungkan, mengkombinasikan dan memadukan sistem pendidikan konvensional dengan sistem yang serba digital. Blended Learning merupakan pembelajaran interaksi secara langsung berupa diskusi langsung dalam proses belajar mengajar

Tahapan Blended Learning dalam Pembelajaran

Secara mendasar terdapat tiga tahapan dasar dalam model Blended Learning yang mengacu pembelajaran berbasis ICT, seperti yang diusulkan oleh Grant Ramsay (2001), yakni: (1) seeking of information, (2) acquisition of information, dan (3) synthesizing of knowledge. Tahapan seeking of information, mencakup pencarian informasi dari berbagai sumber informasi yang tersedia di TIK, memilih secara kritis diantara sumber penyedia informasi dengan berpatokan pada content of relevantion, content of validity/releability, dan academic clarity. Guru berperan sebagai pakar yang dapat memberikan masukan dan nasehat guna membatasi pebelajar dari tumpukan informasi potensial dalam TIK (gadget/smartphone).

Pada tahapan acquisition of information, pebelajar secara individual maupun dalam kelompok kooperatif- 


\section{Yuniarti Maya}

Penggunaan Blended Learning pada Pembelajaran Era Industri 4.0

kolaboratif berupaya untuk menemukan, memahami, serta mengkonfrontasikannya dengan ide atau gagasan yang telah ada dalam pikiran pebelajar, kemudian menginterprestasikan

informasi/pengetahuan dari berbagai sumber yang tersedia, sampai mereka mampu kembali mengkomunikasikan dan menginterpretasikan ide-ide dan hasil interprestasinya menggunakan fasilitas TIK (gadget/smartphone).
Tahap terakhir pembelajaran berbasis TIK adalah tahap synthesizing of knowledge adalah merekonstruksi pengetahuan melalui proses asimilasi dan akomodasi bertolak dari hasil analisis, diskusi dan perumusan kesimpulan dari informasi yang diperoleh. Secara lengkap peran guru dalam pembelajaran sesuai dengan model Blended Learning, dapat dipaparkan seperti pada Tabel 1.

Tabel 1. Sintak Model Blended Learning

\begin{tabular}{|c|c|}
\hline Sintak & Peran Guru \\
\hline (1) & (2) \\
\hline $\begin{array}{l}\text { Fase: seeking of information } \\
\text { Pencarian informasi sains (fisika) dari } \\
\text { berbagai sumber informasi yang } \\
\text { tersedia di TIK (online), buku, } \\
\text { maupun } \\
\text { pendemonstrasian fenomena empirik } \\
\text { sains melalui face to face di kelas }\end{array}$ & $\begin{array}{l}\text { Guru menyampaikan kompetensi dan tujuan } \\
\text { pembelajaran untuk menginisiasi kesiapan } \\
\text { belajar peserta didik sekaligus mempersiapkan } \\
\text { peserta didik dalam proses eksplorasi konsep } \\
\text { sains yang relevan melalui kegiatan } \\
\text { pembelajaran tatap muka (face to face) di kelas } \\
\text { maupun pembelajaran dengan suplemen TIK } \\
\text { (online). Kegiatan eksplorasi konsep dapat } \\
\text { dilakukan secara individual maupun kelompok } \\
\text { Guru memfasilitasi, membantu, dan mengawasi } \\
\text { peserta didik dalam proses eksplorasi konsep } \\
\text { materi yang akan dibahas, sehingga informasi } \\
\text { yang diperoleh tetap relevan dengan topik sains } \\
\text { (fisika) yang sedang dibahas, serta diyakini } \\
\text { validitas/reliabilitas dan akuntabilitas } \\
\text { akademiknya. }\end{array}$ \\
\hline $\begin{array}{l}\text { Fase: acquisition of information } \\
\text { Menginterprestasi dan mengelaborasi } \\
\text { informasi secara personal maupun } \\
\text { komunal }\end{array}$ & $\begin{array}{l}\text { Guru membimbing peserta didik mengerjakan } \\
\text { LKS dalam diskusi kelompok untuk } \\
\text { menginventarisasi informasi, menginterpretasi } \\
\text { dan mengelaborasi konsep materi menuju } \\
\text { pemahaman terhadap topik materi yang sedang } \\
\text { dibelajarkan. } \\
\text { Guru mengkonfrontasi ide atau gagasan yang } \\
\text { telah ada dalam pikiran peserta didik dengan } \\
\text { hasil interprestasi informasi/pengetahuan dari } \\
\text { berbagai sumber yang tersedia. } \\
\text { Guru mendorong dan memfasilitasi peserta } \\
\text { didik untuk mengkomunikasikan hasil } \\
\text { interprestasi dan elaborasi ide-ide materi secara }\end{array}$ \\
\hline
\end{tabular}




\section{Yuniarti Maya}

Penggunaan Blended Learning pada Pembelajaran Era Industri 4.0

\begin{tabular}{|c|c|}
\hline & $\begin{array}{l}\text { tatap muka (face to face) maupun } \\
\text { menggunakan fasilitas TIK (online), secara } \\
\text { kelompok maupun personal. } \\
\text { Guru men-scaffolding peserta didik dalam } \\
\text { mengerjakan soal-soal materi baik } \\
\text { personal maupun dalam kelompok } \\
\text { Guru menugaskan peserta didik untuk } \\
\text { mengelaborasi penguasaan konsep sains } \\
\text { melalui pemberian soal-soal materi yang } \\
\text { bersifat terbuka dan kaya (open-rich problem). }\end{array}$ \\
\hline $\begin{array}{l}\text { Fase: synthesizing of knowledge } \\
\text { Merekonstruksi pengetahuan melalui } \\
\text { proses asimilasi dan akomodasi } \\
\text { bertolak dari hasil analisis, diskusi } \\
\text { dan perumusan kesimpulan dari } \\
\text { informasi yang diperoleh }\end{array}$ & $\begin{array}{l}\text { Guru menjustifikasi hasil eksplorasi dan } \\
\text { akuisasi konsep secara akademik, dan bersama- } \\
\text { sama peserta didik menyimpulkan konsep yang } \\
\text { dibelajarkan. } \\
\text { Guru membantu peserta didik mensintesis } \\
\text { pengetahuan dalam struktur kognitifnya } \\
\text { Guru mendampingi peserta didik dalam } \\
\text { mengkonstruksi/merekonstruksi konsep melalui } \\
\text { proses akomodasi dan asimilasi bertolak dari } \\
\text { hasil analisis, diskusi dan perumusan } \\
\text { kesimpulan terhadap informasi materi yang } \\
\text { diajarkan }\end{array}$ \\
\hline
\end{tabular}

(Diadaptasi dari Grant,2001) 


\section{Manfaat dan Temuan Blended Learning dalam Pembelajaran}

Dengan adanya Blended

Learning pembelajaran dapat dilakukan dimana saja dan kapan saja menggunakan internet. Peserta didik dapat mengakses materi secara leluasa dan dituntut dapat belajar secara mandiri karena bahan ajar tersimpan secara online. Antara guru dan yang diajar dapat memberikan feedback baik berupa pertanyaan dan saran secara realtime. Sehingga diskusi serta tanya jawab antara guru dan peserta didik tidak hanya berlangsung di jam pelajaran namun juga dapat berlangsung di luar jam pelajaran. Guru juga dapat mengontrol pelajaran pserta didik, pserta didik juga dapat menggali materi yang akan disampaikan dan proses pemberiaan tugas pendukung dapat diinformasikan dengan lebih mudah. Tentunya proses belajar mengajar menjadi lebih efisien dan lebih efektif karena komunikasi dan interaksi antara guru dan peserta didik dapat terus terjadi bukan hanya saat jam pelajaran.

Dari hasil penelitian yang menggunakan Blended Learning dalam pembelajaran yaitu: (1) pebelajar lebih termotivasi belajar dengan dukungan TIK (gadget/smartphone), (2) aktivitas dan keterlibatan belajar lebih tinggi karena TIK (gadget/smartphone) lebih interaktif dan menantang, (3) ICT menyediakan potensi sumber informasi yang sangat luas, (4) dapat memvisualisasikan model kompleks sehingga memudahkan pemahaman, (5) dapat melakukan tugas berulang secara cepat dan akurat, (6) proses belajar dapat melampaui ruang dan waktu, dan (7) dapat menampilkan rancangan pembelajaran yang lebih kreatif, interaktif dan inovatif, serta (8) meningkatnya hasil belajar pserta didik. Hal ini didukung oleh beberapa hasil penelitian yang menunjukkan efektivitas pemanfaatan TIK dalam meningkatkan efektivitas dan efisiensi pembelajaran. Prayitno (2015 dan Bibi (2015) menemukan bahwa pemanfaatan blended learning sebagai inovasi teknologi pembelajaran dengan pemodelan simulasi secara signifikan dapat meningkatkan hasil belajar dan literasi komputer peserta didik.

Selain manfaat dari penggunaan

Blended Learning sebagai sebuah kombinasi pengajaran langsung (face-toface) dan pengajaran online, tapi lebih daripada itu adanya temuan elemen dari interaksi sosial yaitu:

1. Adanya interaksi antara guru dan peserta didik

2. Pengajaran pun bisa secara online ataupun tatap muka langsung

3. Blended Learning = combining instructional modalities (or delivery media),

4. Blended Learning = combining instructional methods

\section{SIMPULAN}

Blended learning adalah model belajar masa kini dan masa depan pendidikan. Ini adalah salah satu fitur utama dari reformasi pendidikan modern, dengan blended learning membantu mempersonalisasi pendidikan, dan memungkinkan peserta didik untuk menjadi lebih produktif. Peserta didik memadukan penggunaan teknologi dengan instruksi tatap muka sebagai sarana berkolaborasi dan memperluas pengalaman belajar.

Pembelajaran blended learning yang merupakan program pendidikan yang memungkinkan siswa belajar melalui konten dan petunjuk yang disampaikan secara daring dengan kendali mandiri terhadap waktu, tempat, urutan, maupun kecepatan belajar.

Dengan blended learning melalui studi kasus kehidupan nyata, sumber daya dan dukungan praktis akan dapat membantu peserta didik mengelola identitas online dan informasi digital yang diperlukan untuk pekerjaan mereka di masa mendatang. Dengan blended learning akan menunjukkan bagaimana membantu peserta didik untuk membuat konten digital dan memberi alat untuk berkomunikasi secara efektif dan bekerja secara kolaboratif yang dapat meningkatkan prestasi belajar peserta didik.

\section{DAFTAR PUSTAKA}

Airlangga Hartarto, "Siaran Pers Making Indonesia 4.0: Strategi RI Masuki Revolusi Industri Ke4".

https://kemenperin.go.id/artikel /18967/Making-Indonesia-4.0:Strategi-RI-Masuki-Revolusi$\underline{\text { Industri-Ke-4 }}$

Bibi, Sarah. 2015. "Efektivitas Model Blended Learning Terhadap 
Motivasi Dan Tingkat

Pemahaman Mahasiswa Mata

Kuliah Algoritma Dan

Pemrograman". Jurnal

Pendidikan Vokasi. Vol. 5,

Nomor 1, Februari 2015

Depdiknas. 2003. Undang-undang RI No.20 tahun 2003 Tentang

Sistem Pendidikan Nasional.

Grant Ramsay. 2001. Teaching and Learning With Information and Communication Technology: Succes Through a Whole School Approach. National Educational Computing Conference, July 25-27. Chicago

Kemendikbud, 2016. Kementerian Pendidikan dan Kebudayaan (Kemendikbud) merilis pencapaian nilai Programme for International Student Assessment (PISA).

Prayitno, Wendhie. 2015. "Implementasi Blended Learning Dalam Pembelajaran Pada Pendidikan Dasar Dan Menengah". Jogjakarta

Semler, S. (2005). Use Blended Learning to Increase Learner
Engagement and Reduce
Training Cost. 